\title{
Proteomic Analysis of O-GlcNAc Modifications Derived from Streptozotocin and Glucosamine Induced $\beta$-cell Apoptosis
}

\author{
Jungeun Park' ${ }^{1}$, Hyejin Kwon ${ }^{1}$, Yup Kang ${ }^{3}$ and Youngsoo Kim ${ }^{1,2, *}$ \\ ${ }^{2}$ Cancer Research Institute and ${ }^{1}$ College of Medicine, Seoul National University, Yongon-Dong, Seoul 110-799, Korea \\ ${ }^{3}$ Insitute for Medical Sciences, Ajou University School of Medicine, Wonchon-dong san 5, Suwon, Kyunggi-do 442-749, Korea
}

Received 20 August 2007, Accepted 25 October 2007

\begin{abstract}
The post-translational modifications of Ser and Thr residues by $\mathrm{O}$-linked $\beta$-N-acetylglucosamine (O-GlcNAc), i.e., O-GlcNAcylation, is considered a key means of regulating signaling, in a manner analogous to protein phosphorylation. Furthermore, it has been suggested that the increased flux of glucose through the hexosamine biosynthetic pathway (HBP) stimulates O-GIcNAcylation, and that this may be responsible for many of the manifestations of type 2 diabetes mellitus. To determine whether excessive O-GlcNAcylation of target proteins results in pancreatic $\beta$ cell dysfunction, we increased nucleocytoplasmic protein O-GIcNAcylation levels in $\beta$ cells by exposing them to streptozotocin and/or glucosamine. Streptozotocin and glucosamine co-treatment increased $O$ GlcNAcylated proteomic patterns as assessed by immunoblotting, and these increases in nuclear and cytoplasmic protein O-GlcNAcylations were accompanied by impaired insulin secretion and enhanced apoptosis in pancreatic $\beta$ cells. This observed $\beta$ cell dysfunction prompted us to examine Akt and Bcl-2 family member proteins to determine which proteins are O-GlcNAcylated under conditions of high HBP throughput, and how these proteins are associated with $\beta$ cell apoptosis. Eventually, we identified ten new $O$-GlcNAcylated proteins that were expressed during $\beta$ cell apoptosis, and analyzed the functional implications of these proteins in relation to pancreatic $\beta$ cell dysfunction.
\end{abstract}

Keywords: Hexosamine biosynthetic pathway, O-glycosylation, Proteomics, $\beta$ cell apoptosis

\section{Introduction}

The modification of Ser and Thr residues of nuclear and cytoplasmic proteins with O-linked $\beta-\mathrm{N}$-acetylglucosamine (O-GlcNAcylation) is one of a growing number of posttranslational modifications thought to regulate protein activity in cells, in a manner analogous to protein phosphorylation (Comer and Hart, 2000). The reversible O-GlcNAcylation of target protein is catalyzed by the nucleocytoplasmic enzyme O-GlcNAc transferase (OGT), which attaches a single OGlcNAc moiety to the hydroxyl group of Ser and Thr residues, whereas O-GlcNAc-selective-N-acetyl $\beta$-D-glucosaminidase (OGlcNAcase) performs the reverse operation (Kreppel et al., 1997; Gao et al., 2001).

Recent studies suggest that the deregulation of O-GlcNAc metabolism may be involved in several human diseases, which include Parkinson's disease, Alzheimer's disease, and diabetes (Tang et al., 2000; Zappia et al., 2004). Because of its diverse intracellular functions as a nutrient sensor and as a regulator of transcription and translation, nuclear translocation, and protein interaction, it has been suggested that O-GlcNAc is one of the causative factors of insulin resistance associated with diabetes mellitus (Akimoto et al., 2005).

When glucose enters the human body, roughly $2-5 \%$ is diverted to the hexosamine biosynthetic pathway (HBP), which produces the high energy species UDP-GlcNAc, an OGT substrate (McClain, 2002). After it was first reported by Marshall et al., increased HBP flux has been found to mediate many of the adverse effects of hyperglycemia (Marshall et al., 1991). Furthermore, since O-GlcNAcylation is dependant on HBP throughput, it is conceivable that excessive OGlcNAcylation reflects a prolonged hyperglycemic state due to increased HBP throughput, and thereby, pancreatic $\beta$ cell dysfunction (Hanover et al., 1999; Liu et al., 2000).

To examine the presumption that excessive O-GlcNAcylation induced by elevated HBP throughput is associated with pancreatic $\beta$ cell dysfunction, we used the following strategy. First, we added glucosamine to increase HBP flux and
*To whom correspondence should be address
Tel: 82-2-3668-7950; Fax: 82-2-741-0253

E-mail: biolab@snu.ac.kr 
produce UDP-GlcNAc (an OGT substrate). Second, we added streptozotocin (STZ), an analogue of $\mathrm{N}$-acetylglucosamine, to increase O-GlcNAcylated protein levels in a pancreatic $\beta$ cell line, and thus, induce hyper O-GlcNAcylation (Konrad et al., 2001).

STZ is an established diabetogenic agent in animal models. Although STZ has toxic side effects that involve nitric oxide induction and DNA alkylation, enhanced sensitivity of $\beta$ cells to STZ is associated with O-GlcNAcase inhibition (Roos et al., 1998; Konrad et al., 2001). In addition, glucosamine is known to increase HBP throughput, ATP depletion, and UDPGlcNAc levels, and has been shown to be a powerful inducer of $\beta$ cell dysfunction (Marshall et al., 2004).

Co-treatment with STZ and glucosamine resulted in marked hyper O-GlcNAcylation of nuclear and cytoplasmic proteins, and it was also observed during this experiment that cotreatment with STZ and glucosamine eventually resulted in impaired insulin secretion and accelerated $\beta$ cell apoptosis.

The observed $\beta$ cell dysfunction resulting from STZ and glucosamine co-treatment prompted us to examine proteins O-GlcNAcylated under conditions of high HBP throughput, and how these proteins are associated with $\beta$ cell dysfunction. Accordingly, we identified O-GlcNAcylated proteins expressed during $\beta$ cell death using proteomics tools, and further analyzed the functional implications of these proteins in relation to pancreatic $\beta$ cell dysfunction.

\section{Materials and Methods}

Reagents. RPMI, fetal bovine serum (FBS), trypsin, and antibiotics were purchased from Life Technologies, Inc. Cell proliferation assay Cell Titer $^{\mathrm{TM}} 96$ Aqueous kits and CellTiter-Glo ${ }^{\mathrm{TM}}$ luminescent cell viability assay kits were purchased from Promega. Mouse monoclonal antibodies for Rat Bcl-XL, Bcl-2 and $\beta$-actin and rabbit anti-GAPDH were obtained from Santa Cruz Biotechnology, and rabbit polyclonal antibodies against rat Akt, phospho-Akt (Ser473), BAD and phospho-BAD (Ser136) were purchased from Cell Signaling Technology. Mouse anti-O-GlcNAc CTD110.6 was obtained from Covance. Polyclonal rabbit anti-human Bim was purchased from Affinity Bioreagents. Horseradish peroxidaseconjugated secondary antibodies were from Santa Cruz Biotechnology, and Annexin V-FITC Apoptosis kits from BD Biosciences. Sequencing-grade modified trypsin was used for protein digestion. Rat insulin kits were purchased from Shibayagi. Other chemicals used for cell culture, SDS-PAGE, peptide extraction, and for MALDI-TOF/TOF sample preparation were purchased from Sigma.

Cell culture. Rat insulinoma INS-1 cells were kindly provided by Dr. Y. Kang (Ajou University), and were grown in RPMI 1640 medium containing $1 \mathrm{mM}$ glucose, $10 \%$ heat inactivated FBS, $50 \mu \mathrm{M}$ 2-mercaptoethanol, $1 \mathrm{mM}$ sodium pyruvate, $10 \mathrm{mM}$ HEPES (pH 7.4), $100 \mu \mathrm{g} / \mathrm{ml}$ streptomycin sulfate, and 100 units $/ \mathrm{ml}$ penicillin at $37^{\circ} \mathrm{C}$ in a $5 \% \mathrm{CO}_{2}$ incubator (Asfari et al., 1992). These cells were initially synchronized by culturing them overnight in serumfree medium supplemented with $0.1 \% \mathrm{BSA}$, and then cultured for
$48 \mathrm{~h}$ in RPMI 1640 medium containing $5 \mathrm{mM}$ glucosamine and/or $0.1 \mathrm{mg} / \mathrm{ml}$ streptozotocin in the presence of $10 \%$ FBS.

Cell viability assay. Cell viability assays were performed using 3(4,5-dimethylthiazol-2-yl)-5-(3-carboxymethoxyphenyl)-2-(4sulfophenyl)-2H-tetrazolium (MTS) (Cell Titer $^{\mathrm{TM}} 96$ Aqueous kit, Promega, Madison, WI). Cells were seeded at $5 \times 10^{4}$ cells $/$ well into 96-well culture plates containing $100 \mu \mathrm{l}$ of culture medium. Following treatment, $30 \mu \mathrm{l}$ of MTS was added to each well and incubated for $2 \mathrm{~h}$. Subsequently, plates were read at $490 \mathrm{~nm}$ using a microplate reader (Multiskan spectrum).

Insulin secretion assay. The effect of hyper-O-GlcNAcylation on glucose-stimulated insulin secretion was investigated in INS-1 cells. INS-1 cells were seeded in 24-multi-well plates at $1 \times 10^{5}$ cells $/ \mathrm{ml}$. $24 \mathrm{~h}$ prior to the experiments, medium was removed and cells were rinsed with $1 \mathrm{ml} \mathrm{KRBH}$ buffer $(134 \mathrm{mM} \mathrm{NaCl}, 4.7 \mathrm{mM}$ $\mathrm{KCl}, 1.2 \mathrm{mM} \mathrm{KH} \mathrm{PO}_{4}, 1.2 \mathrm{mM} \mathrm{MgSO}, 1 \mathrm{mM} \mathrm{CaCl}, 10 \mathrm{mM}$ HEPES (pH 7.4), $2 \mathrm{mM} \mathrm{NaHCO}$, and $0.5 \%$ BSA), and then incubated in $1 \mathrm{ml}$ of glucose-free KRBH buffer for $1 \mathrm{~h}$. Subsequently, INS-1 cells were incubated with either $16.5 \mathrm{mM}$ glucose (stimulation condition of insulin secretion) in the presence and/or absence of $5 \mathrm{mM}$ glucosamine and/or $0.1 \mathrm{mg} / \mathrm{ml} \mathrm{STZ}$, or $5 \mathrm{mM}$ glucose (basal condition of insulin secretion) (Waeber et al., 1997). In addition, INS-1 cells were incubated with $16.5 \mathrm{mM}$ glucose in the presence of $5 \mathrm{mM}$ glucosamine and $0.1 \mathrm{mg} / \mathrm{ml} \mathrm{STZ}$ and $0.5 \mathrm{mM}$ benzyl-2acetamido-2-deoxy- $\alpha$-D-galactopyranoside (BADGP). Culture media were collected and assayed for insulin by enzyme immunoassay (EIA) using a Rat insulin assay kit (Shibayagi, Shibukawa, Japan).

Determination of apoptosis. To assess apoptosis, cells were incubated with the above-mentioned concentrations of glucosamine and/or STZ at $5 \times 10^{5}$ cells $/ \mathrm{ml}$. Apoptosis was routinely assessed by measuring annexin $\mathrm{V} /$ propidium iodide staining. Cells were incubated with a mixture of fluorescein-conjugated annexin $\mathrm{V}$ and propidium iodide at room temperature for $15 \mathrm{~min}$ in the dark and were then immediately analyzed using a fluorescence-activated cell sorter with a double fluorescence facility (Beckman Coulter).

Two-dimensional gel electrophoresis (2-DE). Five hundred $\mu \mathrm{g}$ of total proteins, prepared from INS-1 cells, were solubilized in rehydration buffer (7 M urea, $2 \mathrm{M}$ thiourea, 2\% CHAPS, $60 \mathrm{mM}$ DTT, $0.5 \%$ Pharmalyte (pH 3-10), 0.002\% bromophenol blue). Isoelectric focusing was performed using pre-cast immobilized $\mathrm{pH}$ gradient (IPG) strips (18 cm, pH 3-10, linear, Amersham Pharmacia Biotech), and focused for a total of $44 \mathrm{kV}-\mathrm{h}$ at $20^{\circ} \mathrm{C}$. After isoelectric focusing, strips were equilibrated for $30 \mathrm{~min}$ in a reducing solution $(50 \mathrm{mM}$ Tris $\mathrm{HCl}(\mathrm{pH} 8.8), 6 \mathrm{M}$ urea, 30\% (v/v) glycerol, $2 \%(\mathrm{w} / \mathrm{v}) \mathrm{SDS}, 1 \%(\mathrm{w} / \mathrm{v})$ DTT), and then equilibrated for a further $30 \mathrm{~min}$ in an alkylating solution, which was identical to the reducing solution except that the DTT was substituted by $2.5 \%$ $(\mathrm{w} / \mathrm{v})$ iodoacetamide. Gel electrophoresis in the second dimension was performed using a standard SDS-PAGE protocol and the Ettan DALT 6 System (Amersham Pharmacia Biotech).

Immunoblotting. INS-1 cells were lysed with modified RIPA buffer. Equal amounts of proteins were separated by SDS-PAGE and transferred to PVDF membranes, which were then blocked 
with $5 \%$ BSA $(\mathrm{w} / \mathrm{v})$ in TBST $0.1 \%$ for $2 \mathrm{~h}$ at room temperature. To produce 2-DE images, separated protein spots on polyacrylamide gels were electroblotted onto PVDF membranes, which were then incubated overnight at $4^{\circ} \mathrm{C}$ with primary antibodies at a dilution of $1: 1000$. Blots were visualized using peroxidase-conjugated secondary antibodies and an ECL system (Amersham-Pharmacia Biotech). Immunoreactive bands and spots were scanned using an image scanner (GE Biosciences) and intensities were measured using Phoretix 2D image analysis software (Non-Linear Dynamics Inc.).

In-gel trypsin digestion and MALDI-TOF-MS/MS analysis. For MALDI-TOF/TOF MS/MS protein identification, immunoreactive spots that matched spots in silver-stained gel were subjected to ingel digestion, as described previously (Park et al., 2005).

Tryptic peptides were desalted using a GELoader tip (Eppendorf AG, Hamburg) packed with POROS 20 R2 resin (Applied Biosystems). Peptides were loaded to the $\mathrm{R} 2$ resin and washed in water containing $0.1 \%$ TFA. To prepare the sample matrix, $\alpha$ cyano-4-hydroxy cinnamic acid was dissolved in a solution containing $70 \% \mathrm{ACN}$ and $0.1 \% \mathrm{TFA}$ at $5 \mathrm{mg} / \mathrm{ml}$. Elution was performed using $1 \mu \mathrm{l}$ of sample matrix, and eluted peptides were directly spotted individually on the target plate. Samples were analyzed using a MALDI-TOF/TOF mass spectrometer (ABI 4700 Proteomics Analyzer, Applied Biosystems). The unit was operated in MS mode and external calibration was performed using the 4700 calibration mixture; MS/MS data were calibrated against the $\mathrm{m} / \mathrm{z}$ 1570.68 Glu-fibrinopeptide B fragment. MS data were acquired using a Nd:YAG laser $(355 \mathrm{~nm}, 3000$ shots, $200 \mathrm{~Hz}$, at a fixed intensity). The 8 most intense peptides detected in each spot in MS mode were automatically selected for MS/MS analysis. All MS and MS/MS spectra were recorded in positive ion reflector mode. MS/ MS mode was operated at a collision energy of $1-\mathrm{kV}$, and collisioninduced dissociation was performed using air as the collision medium. The signal-to-noise criterion was set at $25^{\circ} \mathrm{C}$ or greater. Resulting data were analyzed using MASCOT in the GPS Explorer 3.0 software package (Applied Biosystems). The MSDB was used for database searching (Applied Biosystems, updated on May 5, 2005). The other database search parameters used for searching were; enzyme trypsin, 1 missed cleavage, variable carbamidomethylation modifications $(\mathrm{C})$, oxidation $(\mathrm{M})$, a peptide tolerance of $0.1 \mathrm{Da}$, an MS/MS tolerance of $0.1 \mathrm{Da}$, a peptide charge of $1+$, and monoisotopic. Only significant hits, as defined by MASCOT probability analysis $(p<0.05)$, were accepted.

Statistical Data analysis. All results shown in the figures represent means $\pm \mathrm{SD}$. Comparisons were performed using the Student's $t$ test or by one-way ANOVA using SPSS 12.0 for Windows ${ }^{\circledR}$ (SPSS Korea. Inc., Seoul). $P$ values of $<0.05$ or $<0.01$ were considered significant.

\section{Results}

Effects of streptozotocin and/or glucosamine on $O$ GlcNAcylation and cell viability. The effects of STZ and/or glucosamine on the levels of O-GlcNAcylation in total INS-1 cell extracts were determined by immunoblotting using O-
$5 \mathrm{mM} \mathrm{GlcN}+0.1 \mathrm{mg} / \mathrm{ml} \mathrm{STZ}$

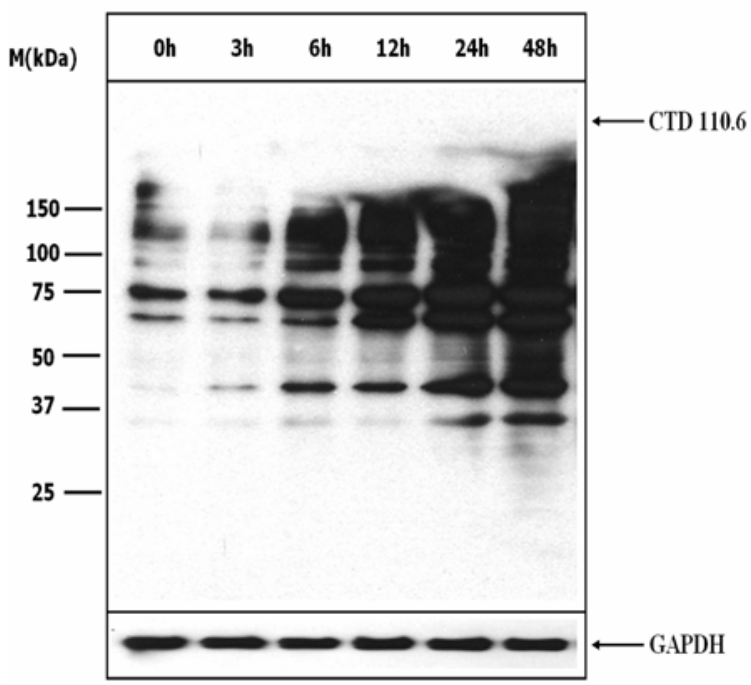

Fig. 1. Effects of streptozotocin and/or glucosamine on levels of OGlcNAcylation in INS-1 cells. INS-1 cells were cultured in presence of $0.1 \mathrm{mg} / \mathrm{ml} \mathrm{STZ}$ and/or $5 \mathrm{mM}$ glucosamine. Equal amounts of cell lysates were separated by $10 \%$ SDS-PAGE and immunoblotted with CTD110.6 (an O-GlcNAc specific antibody). Five separate experiments were performed and representative CTD110.6 immunoblots are shown. GAPDH was used as a loading control. Cellular O-GlcNAc levels increased in a time dependent manner in the presence of STZ and/or glucosamine versus baseline. Molecular weight markers are shown on the left vertical axis.

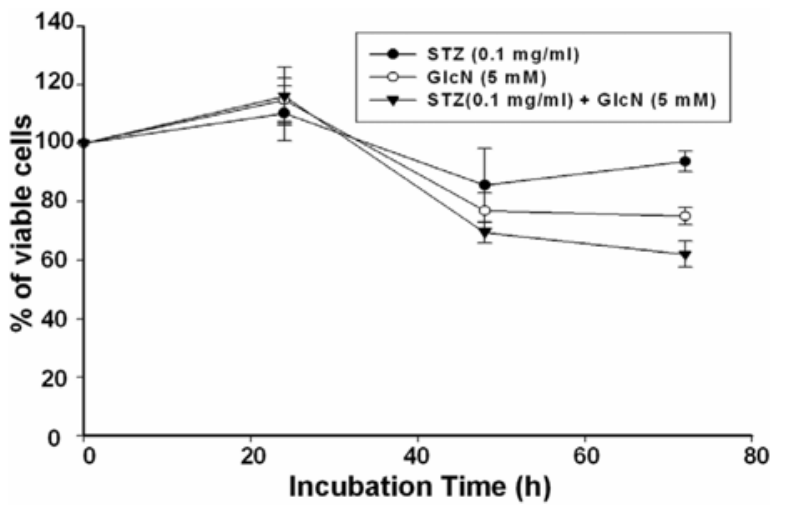

Fig. 2. Effects of streptozotocin and/or glucosamine on INS-1 cell viability. Cell viabilities were determined spectrophotometrically using MTS assays (formazan absorbance was measured at $490 \mathrm{~nm}$ ). INS- 1 cells were cultured for 24,48 , or $72 \mathrm{~h}$ in the presence or absence of glucosamine and/or STZ in medium containing $10 \%$ FBS. The results shown are means \pm SDs of five independent experiments.

GlcNAc-specific antibody (Fig. 1). O-GlcNAc modification of proteins in INS-1 cells accumulated in the STZ $(0.1 \mathrm{mg} / \mathrm{ml})$ plus glucosamine $(5 \mathrm{mM})$ exposed cells in a time dependent manner. In addition, prolonged incubation with STZ and/or glucosamine affected pancreatic $\beta$-cell viability (Fig. 2). STZ or glucosamine at the above-mentioned concentrations reduced 


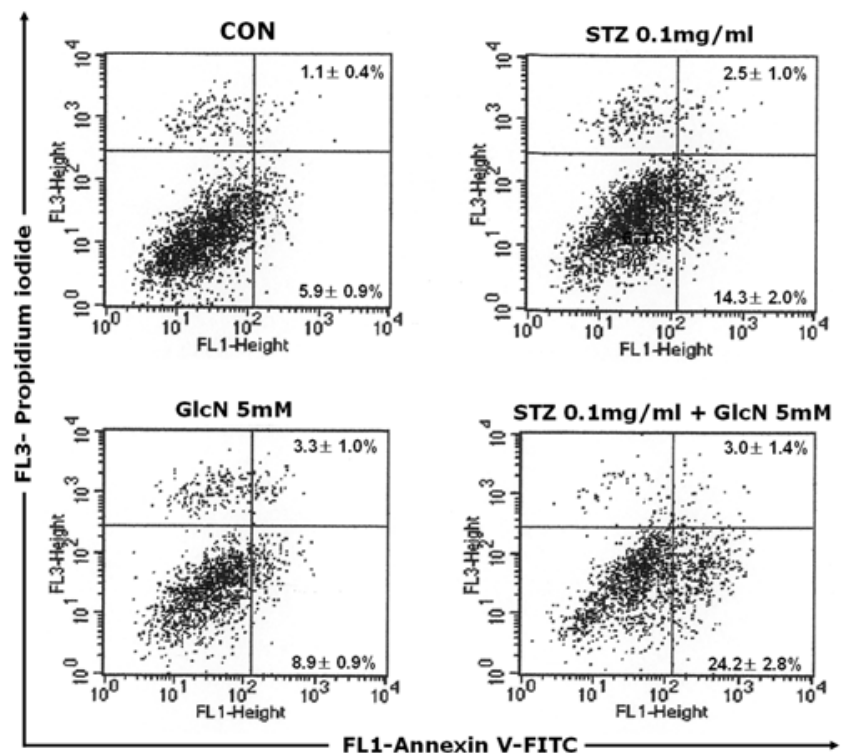

Fig. 3. Effects of streptozotocin and/or glucosamine on apoptotic cell death in INS-1 cells. INS- 1 cells were incubated in the presence of the indicated combinations of STZ and/or glucosamine for $48 \mathrm{~h}$. Data are presented as dual parameter contour plots of FL1 or annexin $\mathrm{V}$ fluorescence (x axis) versus propidium iodide or FL3 fluorescence (y axis). Early apoptotic cells (ANX-V-positive/PInegative) are shown in the lower right quadrant while late apoptotic and necrotic cells migrated are shown in the upper right quadrant (ANX-V-positive/PI-positive). Percentages in the two right quadrants represent fractions of cells in early and late apoptotic stages, respectively.

INS- 1 cell viability to $85.6 \%$ or $76.9 \%$ relative to the untreated control at $48 \mathrm{~h}$, respectively. We also found that INS-1 cell viability was more sensitive to $\mathrm{STZ}+$ glucosamine (at the above concentrations) than to the individual treatments. INS-1 $\beta$-cell viabilities reduced to $69.2 \%$ and $62 \%$ after 48 and $72 \mathrm{~h}$ of $\mathrm{STZ}+$ glucosamine treatment, respectively, indicating synergism between STZ and glucosamine.

Increased O-GlcNAcylation may be associated with apoptotic cell death and impaired insulin secretion. Because increased O-GlcNAcylation represents a hyperglycemic condition, we investigated whether this modification triggers beta cell dysfunction. Accordingly, we examined $\beta$ cell apoptosis by flow cytometry and insulin secretion by EIA. Flow cytometry revealed that $0.1 \mathrm{mg} / \mathrm{ml} \mathrm{STZ} \mathrm{or} 5 \mathrm{mM}$ glucosamine resulted in apoptotic cell populations of $16.8 \%$ and $12.2 \%$, respectively, whereas treatment with STZ+ glucosamine resulted in a $27.2 \%$ apoptotic population (Fig. 3), indicating that STZ and/or glucosamine reduce $\beta$ cell viability by inducing apoptosis.

One unique role of pancreatic $\beta$ cells concerns the coupling of insulin secretion to the glucose metabolism. We assessed insulin levels in glucosamine and/or STZ treated INS-1 cells after stimulating insulin secretion by treating cells with 16.5

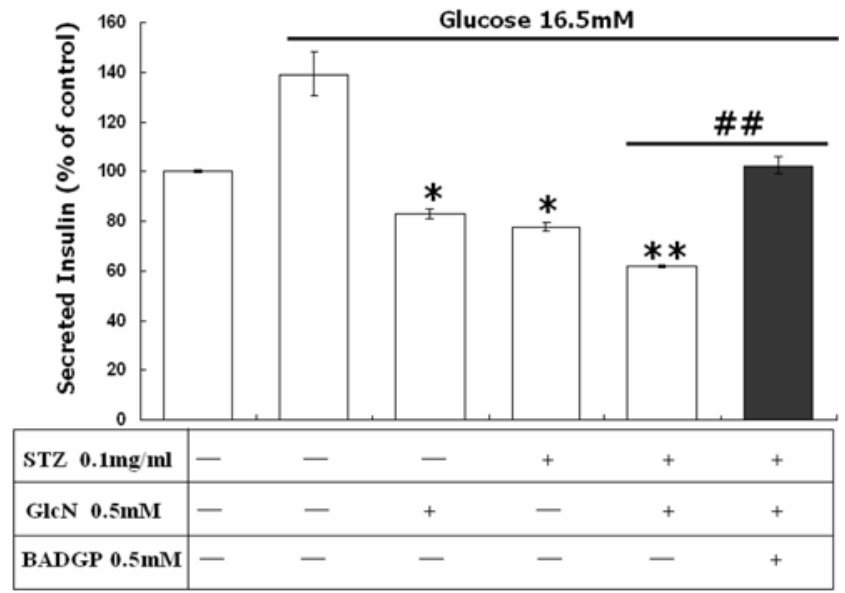

Fig. 4. Effects of streptozotocin and/or glucosamine on insulin secretion in INS- 1 cells. INS- 1 cells were incubated for $24 \mathrm{~h}$ with either $16.5 \mathrm{mM}$ glucose (stimulation condition) in the presence and/

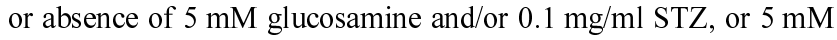
glucose (basal condition), as indicated in the lower panels. In addition, INS-1 cells at $16.5 \mathrm{mM}$ glucose were incubated for $24 \mathrm{~h}$ with STZ and/or glucosamine and $0.5 \mathrm{mM}$ BADGP. Culture media were collected and assayed for insulin using a rat insulin assay kit. Insulin secretions by INS-1 cells are shown as percentages versus basal condition ( $5 \mathrm{mM}$ glucose (left most bar) was considered as $100 \%$ at $24 \mathrm{~h}$ ). The results shown are the means \pm SDs of five independent experiments. Probabilities of $p<0.05, p<0.01$ or $p<0.001$ were considered significant. $*, p<0.05$, **, $p<0.01 v s$. glucose treated cells, and ${ }^{\# \#}, p<0.01 v s$. STZ + glucosamine treated cells.

$\mathrm{mM}$ glucose (c.f. $5 \mathrm{mM}$ glucose in the basal condition) (Waeber et al., 1997). Hyper-O-GlcNAcylated cells showed reduced insulin secretion at all times in STZ and/or glucosamine treated cells versus control cells treated with glucose only (Fig. 4). The observation that treatments with STZ and/or glucosamine increased apoptotic populations and reduced insulin secretion suggests that the O-GlcNAcylation of nucleocytoplasmic proteins is associated with pancreatic $\beta$ cell physiology.

It was not possible to obtain direct evidence of a relationship between increased O-GlcNAc levels and $\beta$ cell dysfunction by inhibiting O-GlcNAcylation reaction, because of the lack of a specific OGT inhibitor. Thus, we investigated the relationship between O-GlcNAcylation and $\beta$ cell dysfunction as follows. Initially, INS-1 cells cultured at $16.5 \mathrm{mM}$ glucose were treated with STZ + glucosamine in the presence or absence of $0.5 \mathrm{mM}$ benzyl-2-acetamido-2-deoxy- $\alpha$-D-galactopyranoside (BADGP) to attenuate O-GlcNacylation (Fig. 4). BADGP has been shown to limit O-glycosylation by preventing the addition of $\mathrm{N}$-acetylglucosamine to target proteins, although BADGP has not been validated as a specific inhibitor of OGT activity (D'Alessandris et al., 2004). Interestingly, BADGP was found to reduce the O-GlcNAcylation activity of OGT when GAPDH was used as a substrate protein (refer to supplementary Figs. $\mathrm{S} 1$ and S2). Moreover, it was found that the insulin secretion in 
(A)
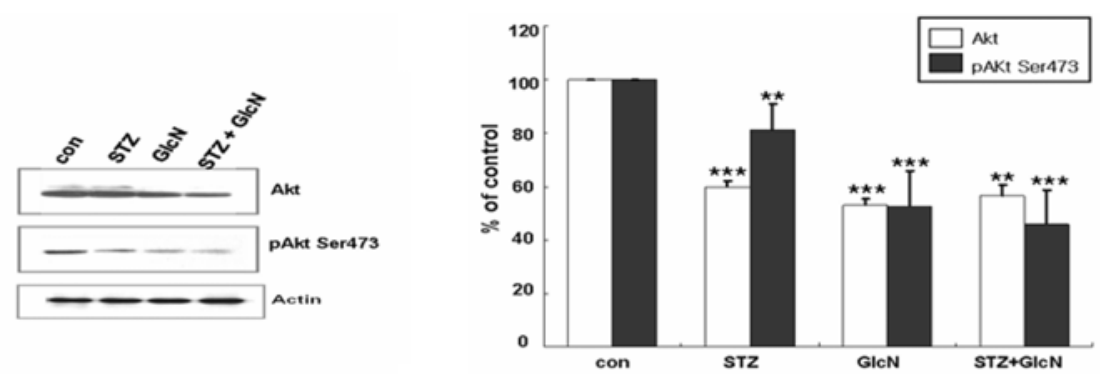

(B)
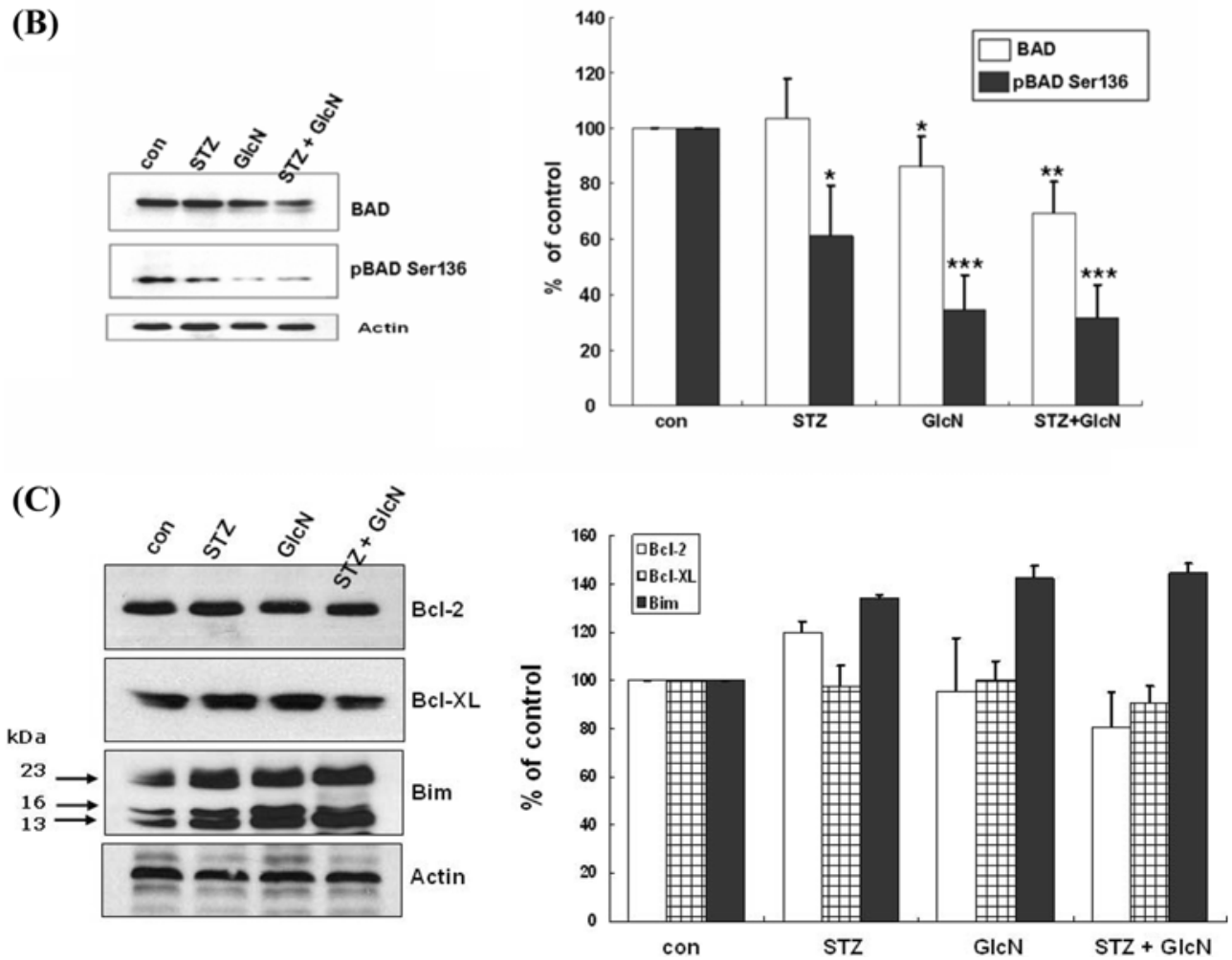

Fig. 5. Effects of streptozotocin and/or glucosamine on the expressions and phosphorylations of Akt and Bcl-2 family proteins in INS-1 cells. INS-1 cells were cultured in the presence of $0.1 \mathrm{mg} / \mathrm{ml} \mathrm{STZ} \mathrm{and/or} 5 \mathrm{mM}$ glucosamine for $48 \mathrm{~h}$. Total proteins $(20 \mu \mathrm{g})$ were then immunoblotted, as described in Materials and Methods. Increased O-GlcNAcylation reduced the protein expressions and phosphorylations of (A) Akt and (B) BAD. (C) Hyper-O-GlcNAcylation in the presence of STZ and glucosamine slightly reduced the expression of Bcl-XL and increased Bim expression. Densitometry of Akt, BAD and Bcl-2 family bands were normalized versus actin, as shown in the bar graphs on the right hand side of the blots. The results shown are the means \pm SDs of five independent experiments. Probabilities of $p<0.05, p<0.01$ or $p<0.001$ were considered significant. ${ }^{*}, p<0.05,{ }^{* *}, p<0.01,{ }^{* *}, p<0.01$ vs. the untreated control.

the presence of STZ + glucosamine was recovered approximately to the basal level ( $5 \mathrm{mM}$ glucose) after adding BADGP (Fig. 4). In addition, $\beta$ cell apoptosis was $13.6 \%$ for $\mathrm{STZ}+$ glucosamine + BADGP compared to $27.2 \%$ for STZ + glucosamine (data not shown). The observation that STZ and/ or glucosamine increased the apoptotic population and reduced insulin secretion supports the notion that the OGlcNAcylation of nucleocytoplasmic proteins is associated with pancreatic $\beta$ cell physiology.

Effects of streptozotocin and/or glucosamine on Akt and Bcl-2 family members in INS-1 cells. Based on the finding that increases in nuclear and cytoplasmic protein $\mathrm{O}-$ GlcNAcylation are accompanied by impaired insulin secretion and enhanced apoptosis in pancreatic $\beta$ cells, we further investigated the increased susceptibility to apoptosis induced by hyper-O-GlcNAcylation, by examining changes in the phosphorylation of Akt and in its downstream cascade. Accordingly, lysates from glucosamine and/or STZ treated INS-1 cells were immunoblotted with anti-Akt, anti-phosphoAkt, anti-BAD, anti-phospho-BAD, anti-Bcl-2, anti-Bcl-XL or anti-Bim antibodies (Figs. 5A, 5B, 5C).

The Akt pathway is activated by different kinds of stimulators after the phosphorylation of Akt at Thr308 and Ser473 in its 
carboxy-terminal region (Kandel and Hay, 1999). In addition, a recent study reported that Akt is constitutively modified with O-GlcNAc and that treatment with O-(2-acetamido-2deoxy-D-glucopyranosylidene) amino N-phenyl carbamate (PUGNAc; a specific O-GlcNAcase inhibitor) increased cytosolic O-GlcNAcylated Akt levels (Gandy et al., 2006).

INS-1 cells incubated with glucosamine $(5 \mathrm{mM})$ and/or STZ $(0.1 \mathrm{mg} / \mathrm{ml})$ showed reduced total Akt protein levels and reduced phosphorylation of Akt at Ser473 (Fig. 5A). Thus, it seems that enhanced O-GlcNAcylation at Akt at Ser473 might lead to a reduction in the level of phosphorylated Akt.

Having observed a decrease in Akt phosphorylation and an increase in $\beta$ cell apoptosis after STZ and/or glucosamine treatment (Fig. 2), we next assessed the effects of less phosphorylated Akt on the activation of cell death by examining Bcl-2 family members, i.e., Bcl-2 and its homologues, Bcl$\mathrm{XL}$, BAD, and Bim (Bcl-2 and Bcl-XL are anti-apoptotic oncoproteins (Hsu et al., 1997), whereas BAD and Bim by forming heterodimers with anti-apoptotic proteins like Bcl-2 and Bcl-XL have pro-apoptotic effects (Ottilie et al., 1997; Hsu et al., 1998).

STZ $(0.1 \mathrm{mg} / \mathrm{ml})$ and/or glucosamine $(5 \mathrm{mM})$ were added to INS-1 cells and BAD, Bim, Bcl-2 and Bcl-XL protein expressions were measured $48 \mathrm{~h}$ later. It was found that $\mathrm{Bim}$ (pro-apoptotic) expression increase slightly but that Bcl-2 and Bcl-XL expressions were unaltered. Interestingly, BAD (proapoptotic) expression tended to reduce in STZ and/or glucosamine treated cells and its phosphorylation status was dramatically reduced by about $80 \%$ (Fig. 5B). It has been well established that the growth factor stimulated activation of the PI3K/Akt signaling pathway culminates in the phosphorylation of the Bcl-2 protein family member BAD (Datta et al., 1997). The above results may suggest that defects in Akt activation reduced phosphorylation of BAD at Ser136 and enhanced apoptosis.

Elevated O-GlcNAcyation may interfere with Akt signaling. Our data indicate that treatment with STZ $(0.1 \mathrm{mg} / \mathrm{ml})$ and/or glucosamine $(5 \mathrm{mM})$ influence O-GlcNAcyation, insulin secretion, and apoptosis in $\beta$ cells. To confirm these results, we used PUGNAc to selectively inhibit O-GlcNAcase activity, and thereby, to increase O-GlcNAcylation levels (Haltiwanger et al., 1998; Perreira et al., 2006).

Treatment with PUGNAc elevated O-GlcNAc levels, as determined by immunoblotting whole cell lysates with OGlcNAc specific antibody CTD110.6 (Fig. 6A). We then examined whether Akt is negatively regulated by PUGNAcinduced O-GlcNAc upregulation. Immunoblotting with PUGNAc-treated or untreated cell lysates showed that phosphorylation of Akt at Ser473 was inhibited by PUGNAc or PUGNAc + glucosamine compared to the untreated control, although Akt expression levels increased slightly in response to PUGNAc treatment (Figs. 6B and 6C). This finding is in part consistent with our previous result (Fig. 5A) that glucosamine and/or STZ reduced the phosphorylation of Akt
(A)

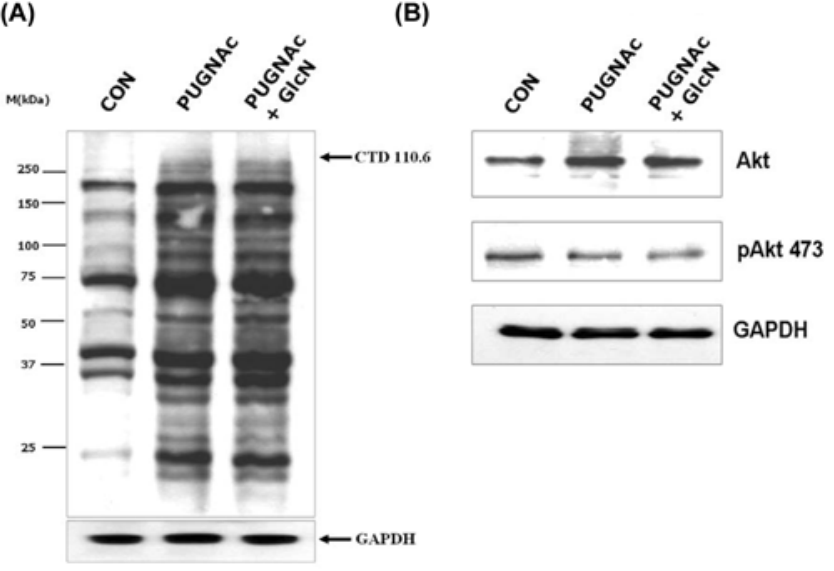

(C)

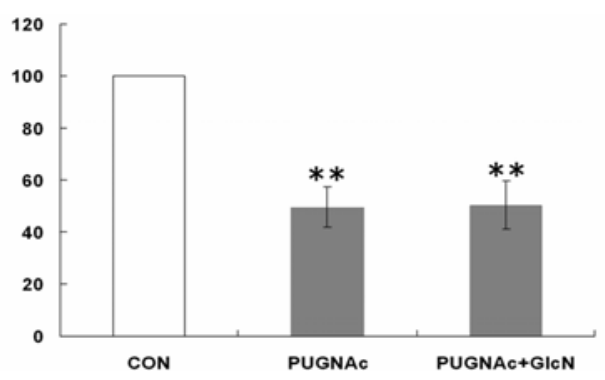

Fig. 6. PUGNAc upregulated O-GlcNAcylation and inhibited Akt phosphorylation. INS-1 cells were cultured in the presence of $0.2 \mathrm{mM}$ PUGNAc or $0.2 \mathrm{mM}$ PUGNAc plus $5 \mathrm{mM}$ glucosamine for $48 \mathrm{~h}$. GAPDH was used as a loading control. (A) Total proteins $(20 \mu \mathrm{g})$ were immunoblotted with GlcNAc antibodies in the control, and in $0.2 \mathrm{mM}$ PUGNAc or $0.2 \mathrm{mM}$ PUGNAc plus $5 \mathrm{mM}$ glucosamine treated INS-1 cells, respectively. (B) Increased OGlcNAcylation reduced the phosphorylation of Akt at Ser473. (C) Densitometric representation of the phosphorylated bands of pAkt Ser473.

at Ser473 and that this was inversely related to O-GlcNAc level. Several previous reports have shown that the effect of PUGNAc on Akt expression is cell type dependent (Vosseller et al., 2002; Arias et al., 2004). Therefore further study will be needed to investigate the relation between O-GlcNAcylation and the Akt signaling pathway.

Identification of O-GlcNAc modified proteins in INS-1 cells. Treatment with $0.1 \mathrm{mg} / \mathrm{ml} \mathrm{STZ}$ and/or $5 \mathrm{mM}$ glucosamine resulted in apoptosis and impaired insulin secretion in INS-1 cells, conceivably because both reagents affect O-GlcNAc accumulation via HBP. Accordingly, we identified OGlcNAcylated proteins differentially expressed after STZ + glucosamine treatment by 2-DE and mass spectrometry (Figs. 7A, 7B).

Proteins in $\mathrm{STZ}+$ glucosamine treated (Fig. 7B) or untreated control INS-1 cells (Fig. 7A) were separated by 2$\mathrm{DE}$ and immunoblotted using antibody specific for the $\mathrm{O}-$ GlcNAc residue. After immunoblotting with O-GlcNAc mAb 
(A)

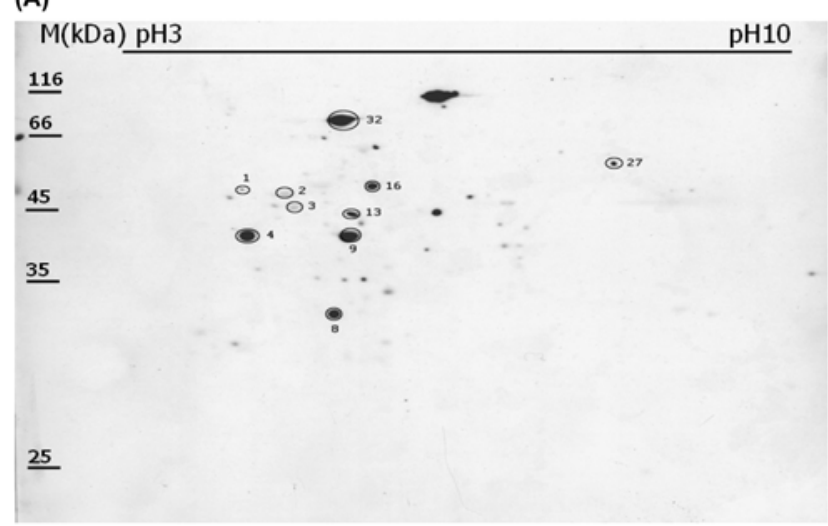

(B)

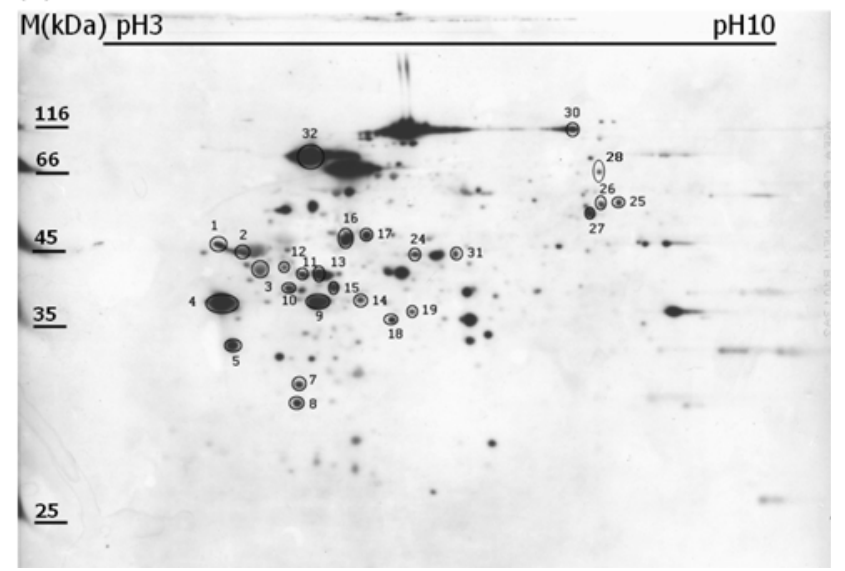

Fig. 7. Immunoblots of O-GlcNAcylated proteins in INS-1 cells treated with STZ and glucosamine. Proteins $(500 \mu \mathrm{g})$ of whole cell lysates were separated by 2-DE, electro-transferred to PVDF membranes, and detected by immunoblotting using O-GlcNAc specific antibody (CTD110.6). Spots immunoreactive to anti-OGlcNAc antibodies on PVDF membranes were scanned using an image scanner and intensities were calculated using Phoretix 2D image analysis software. The upper horizontal axis represents $\mathrm{pI}$ range while the left vertical axis represents molecular weight markers. Five individual western blotting experiments were carried out to ensure consistency. Band intensities were compared to those of untreated controls in order to estimate changes in $\mathrm{O}$ GlcNAcylation (Table 1). Spot numbers match those in Table 1. (A) O-GlcNAcylated proteins were immunoblotted in INS-1 control cells. (B) $0.1 \mathrm{mg} / \mathrm{ml}$ STZ and $5 \mathrm{mM}$ glucosamine were administered to INS-1 cells for $48 \mathrm{~h}$.

CTD110.6, differentially O-GlcNAcylated spots from paired immunoblotting images (STZ + glucosamine treated and nontreated control) were compared using Phoretix 2D image analysis software. Five individual immunoblottings were performed to locate consistently detected spots. Consequently, a total of 23 spots in two representative immunoblots were deemed to be consistently O-GlcNAcylated, and subjected to protein identification by in-gel digestion and mass spectrometry.

The intensities of 21 proteins in the 23 spots increased after $\mathrm{STZ}+$ glucosamine treatment (one spot, spot 8 , decreased in intensity and spot 9 had a similar expression level) (Figs. 7A, 7B, Table 1). Ten consistently detected spots (spots 1, 2, 3, 4, $8,9,13,16,27$ and 32) in control cells were identified by ingel digestion and mass spectrometry (Fig. 7A, Table 1). Compared to untreated control cells, STZ + glucosamine markedly increased the intensities of eight of these proteins (spots 1, 2, 3, 4, 13, 16, 27 and 32), whereas one spot (spot 8) decreased in intensity and spot 9 showed a similar expression level. Interestingly, thirteen proteins (spots 5, 7, 11, 12, 14, 15, $17,18,25,26,28,30$ and 31 ) were found to be newly OGlcNAcylated in STZ + glucosamine treated cells (Figs. 7A, 7B, Table 1).

\section{Discussion}

Increased flux through HBP and increased protein OGlcNAcylation have been reported to cause insulin resistance in vivo and in vitro (Vosseller et al., 2002; Akimoto et al., 2007). In the present study, we examined whether increased O-GlcNAcylation is associated with cell viability and insulin secretion. When INS-1 $\beta$ cells were treated with $0.1 \mathrm{mg} / \mathrm{ml}$ STZ and/or $5 \mathrm{mM}$ glucosamine, apoptotic populations were markedly increased and secreted insulin levels were reduced, compared with those of untreated control cells (Figs. 2 and 4). This result is consistent with previous reports, which showed that increased UDP-GlcNAc levels in nucleocytoplasmic proteins are associated with apoptosis induction and insulin resistance in several tissue culture cell lines (Vosseller et al., 2002; D'Alessandris et al., 2004).

Recently published evidence indicates that Akt activation negatively regulates apoptosis, and furthermore, that $\mathrm{Akt}$ activation in response to insulin stimulation is diminished in cells when O-GlcNAc levels are elevated, although this latter finding remains to be confirmed (Vosseller et al., 2002; Arias et al., 2004). Our results demonstrate that treatment of INS-1 $\beta$ cells (a pancreatic $\beta$ cell line) with STZ and/or glucosamine increases their susceptibility to apoptosis by affecting the Akt survival pathway, by reducing Akt phosphorylation at Ser473.

In our experiment, BAD phosphorylation was dramatically reduced in STZ and/or glucosamine treated cells, suggesting that O-GlcNAcylation detrimentally influences the phosphorylation status of BAD and increases INS-1 apoptosis. One plausible way in which Akt may promote survival is via the inhibition of a component of cell death machinery. In particular, it is conceivable that Akt phosphorylates BAD at Ser136, and thus, blocks BAD induced cell death (Datta et al., 1997). However, siRNA studies are required to determine how the deactivation of Akt is coupled to BAD activation and further to $\beta$ cell apoptosis and insulin secretion. In the present study, we used BADGP to decrease O-GlcNAcylation levels, and found that it recovered the reduced level of secreted insulin downregulated by O-GlcNAcylation. However, it should be note that BADGP has not been shown to be a specific inhibitor of OGT. 
Table 1. O-GlcNAcylated proteins showing expressional changes after co-treatment with STZ and glucosamine

\begin{tabular}{|c|c|c|c|c|c|c|c|}
\hline \multirow{2}{*}{$\begin{array}{l}\text { Spot } \\
\text { No. }\end{array}$} & \multirow{2}{*}{ Protein Name } & \multirow{2}{*}{ Accession No. ${ }^{\mathrm{b}}$} & \multirow{2}{*}{$M r$} & \multirow{2}{*}{$\mathrm{p} I$} & \multirow{2}{*}{ Score $^{c}$} & \multicolumn{2}{|c|}{ Expression Fold $^{d}$} \\
\hline & & & & & & control & $\mathrm{SG}^{\mathrm{e}}$ \\
\hline 1 & Protein disulfide isomerase precursor ${ }^{\mathrm{h}}$ & AAA 40620 & 54033 & 4.9 & 147 & 1 & 9.2 \\
\hline 2 & Tubulin beta chain 15 & A25113 & 49639 & 4.8 & 97 & 1 & 6.2 \\
\hline 3 & $\mathrm{H}+$-transporting two-sector ATPase beta chain & A28701 & 50738 & 4.9 & 119 & 1 & 4.2 \\
\hline 4 & $40 \mathrm{~S}$ ribosomal protein SA $(\mathrm{p} 40)^{\mathrm{h}}$ & AAH60578 & 32672 & 4.8 & 193 & 1 & 2.7 \\
\hline 5 & ATP synthase $\beta$ subunit (fragment) ${ }^{\mathrm{h}}$ & A28701 & 51170 & 4.9 & 96 & $\mathrm{ND}^{\mathrm{f}}$ & $\uparrow_{\mathrm{g}}$ \\
\hline 7 & Annexin A4 (Annexin IV) $)^{\mathrm{h}}$ & ANX4_RAT & 35695 & 5.3 & 95 & ND & $\uparrow$ \\
\hline 8 & Chloride intracellular channel 1 & Q6MG61 & 26963 & 5.1 & 31 & 1 & 0.6 \\
\hline 9 & RAT5MDA NID & AAA40619 & 30135 & 5.1 & 176 & 1 & 1.1 \\
\hline 11 & $\beta$-actin ${ }^{\mathrm{h}}$ & ATRTC & 41723 & 5.3 & 271 & ND & $\uparrow$ \\
\hline 12 & RATCYKER NID ${ }^{\mathrm{h}}$ & AAA 19668 & 52677 & 5.5 & 99 & ND & $\uparrow$ \\
\hline 13 & similar to ubiquinol-cytochrome $\mathrm{c}$ reductase core protein & Q68FY0 & 52815 & 5.6 & 142 & 1 & 2.6 \\
\hline 14 & Ckb protein (Fragment) ${ }^{\mathrm{h}}$ & KIRTCB & 42699 & 5.3 & 89 & ND & $\uparrow$ \\
\hline 15 & Translation initiation factor eIF-4A I ${ }^{\mathrm{h}}$ & Q6P3V8 & 46124 & 5.3 & 187 & ND & $\uparrow$ \\
\hline 16 & Heat shock protein $60^{\mathrm{i}}$ & CAA37654 & 60927 & 5.9 & 73 & 1 & 2.2 \\
\hline 17 & Cct5 protein-Rattus norvegicus & Q68FQ0 & 59498 & 5.5 & 95 & ND & $\uparrow$ \\
\hline 18 & NAD+-specific isocitrate dehydrogenase $\alpha$-subunit & Q99NA5 & 39588 & 6.5 & 32 & ND & $\uparrow$ \\
\hline 25 & Heterogeneous nuclear ribonucleoprotein L & XP_214878 & 63923 & 8.3 & 101 & ND & $\uparrow$ \\
\hline 26 & similar to FYVE finger-containing phosphoinositide kinase & XP_343584 & 40503 & 7.7 & 57 & ND & $\uparrow$ \\
\hline 27 & CCT (chaperonin containing TCP-1) zeta & XP_213765.2 & 57980 & 6.6 & 76 & 1 & 2.3 \\
\hline 28 & similar to RNA helicase ${ }^{\mathrm{h}}$ & $\mathrm{XP} \_228701$ & 80519 & 8.9 & 120 & ND & $\uparrow$ \\
\hline 30 & Translation elongation factor $\mathrm{eEF}-2^{\mathrm{h}}$ & EF2_RAT & 95091 & 6.4 & 61 & ND & $\uparrow$ \\
\hline 31 & Eno1 protein (alpha enolase) $)^{\mathrm{h}}$ & ENOA_RAT & 47098 & 6.2 & 157 & ND & $\uparrow$ \\
\hline 32 & Transitional endoplasmic reticulum ATPase ${ }^{\mathrm{h}}$ & A55190 & 89292 & 5.1 & 106 & 1 & 1.7 \\
\hline
\end{tabular}

${ }^{a}$ Spot numbers were arbitrarily assigned by the Phoretix 2D image analysis program to immunoblotted 2-DE gels, and the numbers used in Figs. 7A and 7B. The spots (10, 19 and 24) were not identified by mass spectrometry.

${ }^{\mathrm{b}}$ Accession numbers represent entries in the NCBI and Expasy databases.

${ }^{\mathrm{c}}$ Scores were calculated using GPS 3.0 in the MASCOT search program.

${ }^{\mathrm{d}}$ Expression folds are the relative expressions of corresponding spot numbers in Figs. 7A and 7B, and represent fold-changes after $48 \mathrm{~h}$ of treatment versus untreated controls that is indicated 1.

${ }^{e} \mathrm{SG}=$ treated with $0.1 \mathrm{mg} / \mathrm{ml} \mathrm{STZ}$ and $5 \mathrm{mM}$ glucosamine for $48 \mathrm{~h}$.

'ND = "not detected".

${ }^{\mathrm{g}}$ Uparrow $=$ protein expressed

${ }^{\mathrm{h}}$ These were previously identified as O-GlcNAc modified proteins. Refer to Love and Hanover, 2005 and Zachara and Hart, 2006 for more comprehensive lists.

'This protein was reported by Kim et al., 2006.

To determine the O-GlcNAcylation levels of proteins in control and STZ and/or glucosamine treated samples, we western blotted with O-GlcNAc specific antibody and identified 23 differentially regulated proteins. Thirteen of these 23 proteins (spots 1, 4, 5, 7, 11, 12, 14, 15, 16, 28, 30, 31 and 32) (Table 1) had been previously identified as O-GlcNAcylated proteins or OGT substrates (Love and Hanover, 2005; Kim et al., 2006; Zachara and Hart, 2006), whereas the other ten were newly identified in this study.

Ten proteins (protein disulfide isomerase precursor, tubulin, $\mathrm{H}^{+}$transporting two sector ATPase, 40S ribosomal protein, chloride intracellular channel 1, RAT5MDA, ubiquinolcytochrome c reductase core protein, heat shock protein 60 , CCT zeta and transitional endoplasmic reticulum ATPase) were identified as O-GlcNAc modified proteins in controls (Fig. 7A) and all, except chloride intracellular channel 1 protein (spot 8) and RAT5MDA (spot 9), were intensively Oglycosylated after $48 \mathrm{~h}$ of treatment with STZ + glucosamine (Fig. 7B).

Five chaperone proteins (protein disulfide isomerase, heat shock protein 60, CCT5, CCT zeta, alpha enolase) were found to be either hyper-O-GlcNAcylated or newly glycosylated in response to STZ + glucosamine treatment. The heat shock proteins have evolutionary conserved structures, which suggests that they have fundamental cellular roles (Guinez et al., 2006). The inductions of these proteins protect against protein misfolding and prevent inter-molecular aggregation under different environmental stresses (Walgren et al., 2003; 


\begin{tabular}{|c|c|}
\hline 2 & Lane \\
\hline 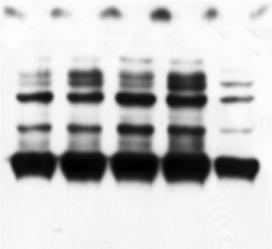 & $\begin{array}{l}\text { 1: Control } \\
\text { 2: GlcN } 5 \mathrm{mM} \\
\text { 3: STZ 0.1 mg/ml } \\
\text { 4: GICN + STZ } \\
\text { 5: GlcN + STZ + } \\
\text { BADGP }\end{array}$ \\
\hline$=-1$ & GAPDH \\
\hline
\end{tabular}

Supplementary Fig. S1. Exposure of INS-1 cells to STZ and/or glucosamine increased intracellular O-GlcNAcylation. INS-1 cells were cultured (as described in the legend of Fig. 1) in presence or absence of STZ and/or glucosamine, or with STZ + glucosamine $+0.5 \mathrm{mM}$ BADGP (lane 5). Equal amounts of cell lysates were separated by $10 \%$ SDS-PAGE and immunoblotted with CTD 110.6 (an O-GlcNAc specific antibody). GAPDH was used a loading control. Cellular O-GlcNAc levels increased in a time dependent manner in the presence of STZ + glucosamine versus the control (lane 1). Interestingly, BADGP (lane 5) suppressed O-GlcNAcylation when co-treated with STZ and glucosamine. All O-GlcNAcylations were measured at $48 \mathrm{~h}$.

Guinez, Losfeld et al., 2006). One enolase was recently described as a heat shock protein and demonstrated to be an early target of oxidative damage (Castegna et al., 2002). Moreover, protein disulfide isomerase influences the folding of proteins using multiple disulfide bonds, by catalyzing the formation, rearrangement, and cleavage of these bonds, and protein disulfide isomerase is known to undergo proteolytic degradation in mammalian cells in response to oxidative stress (Dowling et al., 2006). The role of the hyper-O-GlcNAcylation of these proteins under conditions of high HBP throughput remains unclear, but it may be a response to oxidative stress.

Some energy metabolism-regulated proteins, i.e., $\mathrm{H}^{+}$ transporting two sector ATPase, ATP synthase, ubiquinolcytochrome $\mathrm{c}$ reductase, $\mathrm{NAD}^{+}$specific isocitrate dehydrogenase, and endoplasmic reticulum ATPase, were hyper OGlcNAcylated in STZ + glucosamine treated cells. The ATPases (ATP synthases) are membrane-bound enzyme complexes and ion transporters, which combine ATP synthesis and/or hydrolysis with the trans-membrane transport of protons, and recent studies have reported that glucosamine treatment and elevated HBP throughput cause the intracellular accumulation of glucosamine-6-phosphate and deplete cellular ATP levels (Marshall et al., 2004). Moreover, isocitrate dehydrogenases, which are localized in the mitochondrial matrix, catalyze the oxidative decarboxylation of isocitrate to 2-oxoglutarate (Haggie and Verkman, 2002). In addition, we found that the O-GlcNAcylations of structural and cytoskeletal components (beta-tubulin, annexin IV, beta-actin and keratin; all known OGT substrates) were increased after STZ+ glucosamine treatment, (Love and Hanover, 2005).

O-GlcNAcylated cellular transcription and translation
(A)

(B)

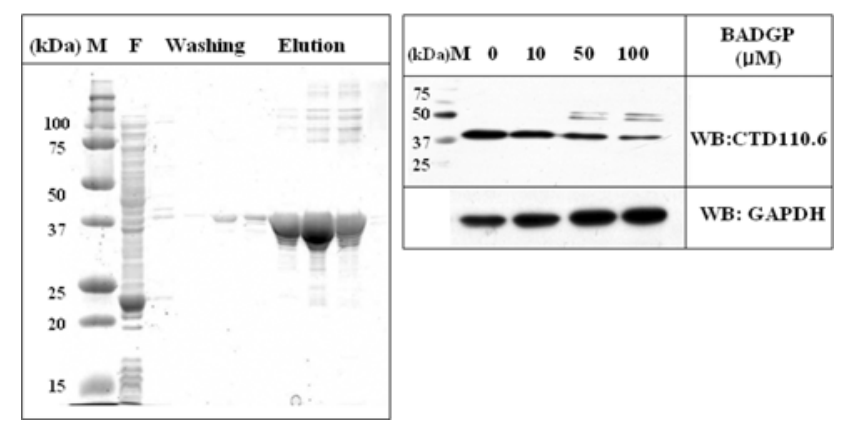

Supplementary Fig. S2. BADGP inhibits the activity of recombinant OGT. The conversion of GAPDH to O-GlcNAcylated GAPDH (middle panel of Fig. S2B) was taken to be a measure of the O-GlcNAcylation activity of OGT. Equal quantities of His-OGT bound to Ni-NTA resins were incubated with the indicated concentrations of BADGP (top panel of Fig. S2B) in the presence of UDP-GlcNAc and purified GAPDH in OGT activity assays at 25 for $90 \mathrm{~min}$, as previous described by Marshall et al. (2003) ('Measurement of UDP-N-acetylglucosaminyl transferase in brain cytosol and characterization of anti-OGT antibodies'. Anal. Biochem. 314, 169-179). (A) Purification of recombinant GAPDH. The left most vertical axis represents molecular markers. The ' $\mathrm{F}$ ' column represents flow-through off the His-NTA column, and column 'Washing' indicates the fraction washed off the column. 'Elution' indicates purified recombinant GAPDH. (B) Immunoblot of O-GlcNAcylated GAPDH after OGT activity assay. OGlcNAcylated GAPDH produced during OGT activity assays was separated by SDS-PAGE on $10 \%$ gel and subsequently immunoblotted using O-GlcNAc specific antibody CTD 110.6. GAPDH used for OGT assays at the indicated BADGP concentrations were confirmed using GAPDH antibody (bottom panel). As BADGP concentrations increased (top panel), OGlcNAcylated GAPDH levels decreased (middle panel). These findings suggest that BADGP inhibits OGT activity, but the specificity of this inhibition has yet to be confirmed.

factors are itemized in Table 1 (RNA helicase, 40S ribosomal proteins, translation initiation factor eIF-4A, translation elongation factor eEF-2). To date, more than 10 transcription factors have been shown to be O-GlcNAcylated at sites required for phosphorylation (Love and Hanover, 2005), and since phosphorylation is required for initiation and elongation complex, this reciprocal relationship between phosphorylation and O-GlcNAcylation is likely to serve as a signal transduction controller. Although function of O-GlcNAcylation is unknown, it has been reported that the O-GlcNAcylations of transcription/ translation factors influences mRNA machinery formation (Jackson and Tjian, 1988; Zachara and Hart, 2006).

The present study identifies a number of O-GlcNAcylated nucleocytoplasmic proteins present under conditions of STZ + glucosamine-induced pancreatic $\beta$ cell apoptosis, and thus, enhances our understanding of the relation between HBP throughput and hyperglycemic type 2 diabetes mellitus. 
Acknowledgments This study was supported by the Korean Health 21 R\&D Project, Ministry of Health \& Welfare, Republic of Korea (\#A050087), and by a SNUH Research Fund grant to Y. Kim (\#03-2005-007).

\section{References}

Akimoto, Y., Hart, G. W., Hirano, H. and Kawakami, H. (2005) OGlcNAc modification of nucleocytoplasmic proteins and diabetes. Med. Mol. Morphol. 38, 84-91.

Akimoto, Y., Hart, G. W., Wells, L., Vosseller, K., Yamamoto, K., Munetomo, E., Ohara-Imaizumi, M., Nishiwaki, C., Nagamatsu, S., Hirano, H. and Kawakami, H. (2007) Elevation of the posttranslational modification of proteins by O-linked $\mathrm{N}$ acetylglucosamine leads to deterioration of the glucose-stimulated insulin secretion in the pancreas of diabetic Goto-Kakizaki rats. Glycobiology 17, 127-140.

Arias, E. B., Kim, J. and Cartee, G. D. (2004) Prolonged incubation in PUGNAc results in increased protein O-Linked glycosylation and insulin resistance in rat skeletal muscle. Diabetes 53, 921930.

Asfari, M., Janjic, D., Meda, P., Li, G., Halban, P. A. and Wollheim, C. B. (1992) Establishment of 2-mercaptoethanol-dependent differentiated insulin-secreting cell lines. Endocrinology 130, 167178 .

Castegna, A., Aksenov, M., Thongboonkerd, V., Klein, J. B., Pierce, W. M., Booze, R., Markesbery, W. R. and Butterfield, D. A. (2002) Proteomic identification of oxidatively modified proteins in Alzheimer's disease brain. Part II: dihydropyrimidinase-related protein 2, alpha-enolase and heat shock cognate $71 . J$. Neurochem. 82, 1524-1532.

Comer, F. I. and Hart, G. W. (2000) O-Glycosylation of nuclear and cytosolic proteins. Dynamic interplay between O-GlcNAc and Ophosphate. J. Biol. Chem. 275, 29179-29182.

D'Alessandris, C., Andreozzi, F., Federici, M., Cardellini, M., Brunetti, A., Ranalli, M., Del Guerra, S., Lauro, D., Del Prato, S., Marchetti, P., Lauro, R. and Sesti, G. (2004) Increased Oglycosylation of insulin signaling proteins results in their impaired activation and enhanced susceptibility to apoptosis in pancreatic beta-cells. FASEB J. 18, 959-961.

Datta, S. R., Dudek, H., Tao, X., Masters, S., Fu, H., Gotoh, Y. and Greenberg, M. E. (1997) Akt phosphorylation of BAD couples survival signals to the cell-intrinsic death machinery. Cell 91, 231-241.

Dowling, P., O'Driscoll, L., O'Sullivan, F., Dowd, A., Henry, M., Jeppesen, P. B., Meleady, P. and Clynes, M. (2006) Proteomic screening of glucose-responsive and glucose non-responsive MIN-6 beta cells reveals differential expression of proteins involved in protein folding, secretion and oxidative stress. Proteomics 6, 6578-6587.

Gandy, J. C., Rountree, A. E. and Bijur, G. N. (2006) Akt1 is dynamically modified with O-GlcNAc following treatments with PUGNAc and insulin-like growth factor-1. FEBS Lett. 580, 30513058.

Gao, Y., Wells, L., Comer, F. I., Parker, G. J. and Hart, G. W. (2001) Dynamic O-glycosylation of nuclear and cytosolic proteins: cloning and characterization of a neutral, cytosolic beta-Nacetylglucosaminidase from human brain. J. Biol. Chem. 276,
9838-9845

Guinez, C., Losfeld, M. E., Cacan, R., Michalski, J. C. and Lefebvre, T. (2006) Modulation of HSP70 GlcNAc-directed lectin activity by glucose availability and utilization. Glycobiology 16, 22-28.

Haggie, P. M. and Verkman, A. S. (2002) Diffusion of tricarboxylic acid cycle enzymes in the mitochondrial matrix in vivo. Evidence for restricted mobility of a multienzyme complex. J. Biol. Chem. 277, 40782-40788.

Haltiwanger, R. S., Grove, K. and Philipsberg, G. A. (1998) Modulation of O-linked $\mathrm{N}$-acetylglucosamine levels on nuclear and cytoplasmic proteins in vivo using the peptide O-GlcNAcbeta-N-acetylglucosaminidase inhibitor O-(2-acetamido-2-deoxyD-glucopyranosylidene)amino-N-phenylcarbamate. J. Biol. Chem. 273, 3611-3617.

Hanover, J. A., Lai, Z., Lee, G., Lubas, W. A. and Sato, S. M. (1999) Elevated O-linked $\mathrm{N}$-acetylglucosamine metabolism in pancreatic beta-cells. Arch. Biochem. Biophys. 362, 38-45.

Hsu, S. Y., Kaipia, A., Zhu, L. and Hsueh, A. J. (1997) Interference of $\mathrm{BAD}$ (Bcl-XL/Bcl-2-associated death promoter)-induced apoptosis in mammalian cells by 14-3-3 isoforms and P11. Mol. Endocrinol. 11, 1858-1867.

Hsu, S. Y., Lin, P. and Hsueh, A. J. (1998) BOD (Bcl-2-related ovarian death gene) is an ovarian $\mathrm{BH} 3$ domain-containing proapoptotic $\mathrm{Bcl}-2$ protein capable of dimerization with diverse antiapoptotic Bcl-2 members. Mol. Endocrinol. 12, 1432-1440.

Jackson, S. P. and Tjian, R. (1988) O-glycosylation of eukaryotic transcription factors: implications for mechanisms of transcriptional regulation. Cell 55, 125-133.

Kandel, E. S. and Hay, N. (1999) The regulation and activities of the multifunctional serine/threonine kinase Akt/PKB. Exp. Cell. Res. 253, 210-229.

Kim, H. S., Kim, E. M., Lee, J., Yang, W. H., Park, T. Y., Kim, Y. M. and Cho, J. W. (2006) Heat shock protein 60 modified with Olinked $\mathrm{N}$-acetylglucosamine is involved in pancreatic beta-cell death under hyperglycemic conditions. FEBS Lett. 580, 23112316.

Konrad, R. J., Mikolaenko, I., Tolar, J. F., Liu, K. and Kudlow, J. E. (2001) The potential mechanism of the diabetogenic action of streptozotocin: inhibition of pancreatic beta-cell O-GlcNAcselective N-acetyl-beta-D-glucosaminidase. Biochem. J. 356, 3141.

Kreppel, L. K., Blomberg, M. A. and Hart, G. W. (1997) Dynamic glycosylation of nuclear and cytosolic proteins. Cloning and characterization of a unique O-GlcNAc transferase with multiple tetratricopeptide repeats. J. Biol. Chem. 272, 9308-9315.

Liu, K., Paterson, A. J., Chin, E. and Kudlow, J. E. (2000) Glucose stimulates protein modification by O-linked GlcNAc in pancreatic beta cells: linkage of O-linked GlcNAc to beta cell death. Proc. Natl. Acad. Sci. USA 97, 2820-2825.

Love, D. C. and Hanover, J. A. (2005) The hexosamine signaling pathway: deciphering the "O-GlcNAc code". Sci STKE 312, 13.

Marshall, S., Bacote, V. and Traxinger, R. R. (1991) Discovery of a metabolic pathway mediating glucose-induced desensitization of the glucose transport system. Role of hexosamine biosynthesis in the induction of insulin resistance. J. Biol. Chem. 266, 4706-4712.

Marshall, S., Nadeau, O. and Yamasaki, K. (2004) Dynamic actions of glucose and glucosamine on hexosamine biosynthesis in isolated adipocytes: differential effects on glucosamine 6phosphate, UDP-N-acetylglucosamine, and ATP levels. J. Biol. Chem. 279, 35313-35319. 
McClain, D. A. (2002) Hexosamines as mediators of nutrient sensing and regulation in diabetes. J. Diabetes Complications 16, 72-80.

Ottilie, S., Diaz, J. L., Horne, W., Chang, J., Wang, Y., Wilson, G., Chang, S., Weeks, S., Fritz, L. C. and Oltersdorf, T. (1997) Dimerization properties of human BAD. Identification of a BH-3 domain and analysis of its binding to mutant $\mathrm{Bcl}-2$ and $\mathrm{Bcl}-\mathrm{XL}$ proteins. J. Biol. Chem. 272, 30866-30872.

Park, J., Kim, S., Oh, J. K., Kim, J. Y., Yoon, S. S., Lee, D. and Kim, Y. (2005) Identification of differentially expressed proteins in imatinib mesylate-resistant chronic myelogenous cells. $J$. Biochem. Mol. Biol. 38, 725-738.

Perreira, M., Kim, E. J., Thomas, C. J. and Hanover, J. A. (2006) Inhibition of O-GlcNAcase by PUGNAc is dependent upon the oxime stereochemistry. Bioorg. Med. Chem. 14, 837-846.

Roos, M. D., Xie, W., Su, K., Clark, J. A., Yang, X., Chin, E., Paterson, A. J. and Kudlow, J. E. (1998) Streptozotocin, an analog of $\mathrm{N}$-acetylglucosamine, blocks the removal of O-GlcNAc from intracellular proteins. Proc. Assoc. Am. Physicians 110, 422-432.

Tang, J., Neidigh, J. L., Cooksey, R. C. and McClain, D. A. (2000) Transgenic mice with increased hexosamine flux specifically targeted to beta-cells exhibit hyperinsulinemia and peripheral insulin resistance. Diabetes 49, 1492-1499.
Vosseller, K., Wells, L., Lane, M. D. and Hart, G. W. (2002) Elevated nucleocytoplasmic glycosylation by O-GlcNAc results in insulin resistance associated with defects in Akt activation in 3T3-L1 adipocytes. Proc. Natl. Acad. Sci.USA 99, 5313-5318.

Waeber, G., Calandra, T., Roduit, R., Haefliger, J. A., Bonny, C., Thompson, N., Thorens, B., Temler, E., Meinhardt, A., Bacher, M., Metz, C. N., Nicod, P. and Bucala, R. (1997) Insulin secretion is regulated by the glucose-dependent production of islet beta cell macrophage migration inhibitory factor. Proc. Natl. Acad. Sci. USA 94, 4782-4787.

Walgren, J. L., Vincent, T. S., Schey, K. L. and Buse, M. G. (2003) High glucose and insulin promote O-GlcNAc modification of proteins, including alpha-tubulin. Am. J. Physiol. Endocrinol. Metab. 284, 424-434.

Zachara, N. E. and Hart, G. W. (2006) Cell signaling, the essential role of O-GlcNAc! Biochim. Biophys. Acta 1761, 599-617.

Zappia, M., Manna, I., Serra, P., Cittadella, R., Andreoli, V., La Russa, A., Annesi, F., Spadafora, P., Romeo, N., Nicoletti, G., Messina, D., Gambardella, A. and Quattrone, A. (2004) Increased risk for Alzheimer disease with the interaction of MPO and A2M polymorphisms. Arch. Neurol. 61, 341-344. 